\title{
O SETOR DE AGRONEGÓCIOS E ALGUNS DE SEUS DESAFIOS
}

Claudio José Donato ${ }^{1}$,Eduardo de Lima Silva ${ }^{2}$,Hualacy Guilherme Odilon do Nascimento ${ }^{3}$,Irene da Silva Caires ${ }^{1}$, Leticia Moreira da Silva ${ }^{4}$, Liége Xavier Martins ${ }^{4}$, Maísa Ferreira Vieira ${ }^{5}$, Tais Muller ${ }^{6}$, Tatiana Veiga Uzeloto ${ }^{7}$

${ }^{1}$ Universidade do Oeste Paulista - UNOESTE, Presidente Prudente, SP. ${ }^{2}$ Universidade de Araraquara - UNIARA, Araraquara, SP. ${ }^{3}$ Universidade do Oeste Paulista - UNOESTE, curso de Especialização em Integração Lavoura-PecuáriaFloresta, Presidente Prudente, SP. ${ }^{4}$ Universidade do Oeste Paulista - UNOESTE, curso de Agronegócio, Presidente Prudente, SP. ${ }^{5}$ Universidade do Oeste Paulista - UNOESTE, Egressa do curso de graduação de Engenharia Civil, Presidente Prudente, SP. ${ }^{6}$ Universidade Estadual de Maringá - UEM, Egressa do curso de graduação de Engenharia Ambiental, Maringá, PR. 'Universidade do Oeste Paulista - UNOESTE, do curso de Gastronomia, Presidente Prudente, SP. E-mail: claudio.donato@hotmail.com

\section{RESUMO}

Diante do novo cenário do agronegócio brasileiro, o presente artigo tem por objetivo analisar, por meio de uma revisão de literatura, os desafios e perspectivas para o agronegócio brasileiro. A metodologia adotada foi uma pesquisa bibliográfica. As considerações teóricas apontadas neste estudo demonstram o agronegócio brasileiro é uma atividade que tem grande representatividade dentro da economia do país. Foi evidenciado que um dos desafios é a garantir maior participação na liberalização comercial, tendo maior contrapartida dos países desenvolvidos, como Estados Unidos e União Europeia visando obter maior ingresso aos mercados agroindustriais internacionais. Maior eficiência dos serviços públicos de infraestrutura, sobretudo a precariedade dos modais de transporte rodoviário são desafios para este setor. Estes estudo conclui que que há necessidade de formulação de políticas públicas quanto privadas, para maior aproveitamento do potencial do agronegócio da sub-região e para a construção do desenvolvimento duradouro e sustentável foi evidenciada nesta pesquisa.

Palavras-chaves: Agronegócio. Desafios. Perspectivas. Desenvolvimento Econômico. Comércio Internacional.

\section{THE AGRIBUSINESS SECTOR AND SOME OF THEIR CHALLENGES}

\begin{abstract}
In view of the new Brazilian agribusiness scenario, this article aims to analyze, through a literature review, the challenges and perspectives for Brazilian agribusiness. The methodology adopted was a bi-biographical research. The theoretical considerations pointed out in this study demonstrate the Brazilian agribusiness is an activity that has great representativeness within the economy of the country. It has been shown that one of the challenges is to ensure greater participation in trade liberalization, with a greater counterpart of developed countries, such as the United States and the European Union, in order to gain greater access to international agroindustrial markets. Greater efficiency of public infrastructure services, especially the precariousness of road transport modes, are challenges for this sector. These studies conclude that there is a need to formulate public as well as private policies in order to make greater use of the subregion's potential in the subregion and to build sustainable and sustainable development.
\end{abstract}

Keywords: Agribusiness. Challenges. Perspectives. Economic development. International Trade. 


\section{INTRODUÇÃO}

A atividade agrícola está intimamente ligada ao processo de desenvolvimento econômico político e social do Brasil desde os primórdios da colonização. A atividade econômica estava devotada para a produção de um gênero de alto valor comercial para o mercado externo, como a cana-de-açúcar, cacau e o café, mas não existia a preocupação com a produção para abastecimento de alimentos para a população local (REDIN;FIALHO, 2010).

$A$ adoção do modelo agroexportador que vigorou até meados do século $X X$ impediu a diversificação da produção. Aliado a isso o intenso processo de urbanização e industrialização a partir da década de 60 levou o governo a implantar mecanismos para modernizá-la a agricultura (PRIORI, 2012).

A modernização do setor agrícola do Brasil, que começou na década de 1960, expandiu com sucesso para a região do cerrado na década de 1980 no âmbito do projeto de modernização e programas conduzidos pelo Estado, possibilitando origem a diferentes formas e práticas de apropriação de terras, criando espaços para o investimento por estrangeiros. Ao longo das últimas três décadas, a produção de soja está sob controle substancial de capital estrangeiro e, nos últimos anos, a produção de cana de açúcar e do investimento estrangeiro na indústria do etanol tem crescido acentuadamente em alguma regiões do país (CLEMENTS;FERNANDES, 2013).

Atualmente, segundo o relatório da Organização das Nações Unidas para a Alimentação e Agricultura (FAO) e da Organização para Cooperação e Desenvolvimento Econômico (OCDE ) divulgado em 2015, o Brasil se tornará o maior exportador de carne bovina e de aves do mundo em 2024. Outro dado relevante do agronegócio brasileiro é que o setor emprega cerca de $13 \%$ da população ativa do país. O relatório também aponta que nos próximos anos haverá tendência de menor crescimento na produção agrícola devido à diminuição dos preços das principais commodities no mundo no mercado internacional e também devido à desaceleração na economia chinesa, pois, a China é um dos maiores parceiros comerciais do Brasil no agronegócio.

Diante deste novo cenário do agronegócio brasileiro, o presente artigo tem por objetivo analisar, por meio de uma revisão sistemática de literatura, os desafios e perspectivas para o agronegócio brasileiro.

\section{METODOLOGIA}

A realização desta investigação científica foi elaborada a partir de uma pesquisa bibliográfica, que visou o levantamento de informações para obter conhecimento existente sobre agronegócio brasileiro.

Para realizar a fundamentação teórica foi realizada uma pesquisa bibliográfica para aprofundar os conceitos e pressupostos teóricos que nortearam essa investigação. Segundo Gil (2007, p.64) a "pesquisa bibliográfica é desenvolvida a partir de material já elaborado, constituído principalmente de livros e artigos científicos".

Neste estudo, para a coleta de dados na literatura foi feito um roteiro para o levantamento bibliográfico. Este roteiro permitirá a identificação das fontes bibliográficas (livros, revistas, jornais, vídeos etc.) importantes à consecução da presente pesquisa.

Esta revisão bibliográfica foi realizada em bancos de dados da Scielo, Lilacs, Bireme, Revista de Economia e Sociologia Rural monografias, teses de doutorado e dissertações de mestrado. As fontes bibliográficas consultadas foram artigos nacionais.

\section{RESULTADOS}

O agronegócio é conceituado como um conjunto que está relacionado com a produção agropecuária. Dito em outras palavras, o agronegócio é caracterizado como atividade que engloba desde os insumos básicos até o produto final. De modo geral é uma atividade econômica que está vinculada com a a produção, transformação, distribuição e comercialização de cadeias produtivas , 
as quais se distinguem em : comercialização, industrialização e a produção de matérias-primas (ROLDÃO ;MACIEL Júnior, 2015). A conceituação de agronegócio foi concebida nos Estados Unidos por John Davis e Ray Goldberg, no final da década de 50, criando o termo agribusiness, visando abordar a agricultura e a pecuária de forma integrada (BATALHA; SILVA, 2007).

No Brasil, o agronegócio ganhou impulso a partir da década de 80 influenciado pela abertura econômica, guiada pela diretriz ideológica neoliberal, cuja principal premissa é o financiamento de recursos originados da iniciativa privada. A falência do estado de Bem- Estar Social (Welfare State), caracterizada pela redução da intervenção estatal na economia, abriu caminhos para que ocorresse um maior fluxo de capitais e de mercadorias no mundo (LIMA et al 2011).

Foi no período de 1970 a 1990 que o Brasil ganhou destaque na produção agrícola mundial, pois, se tornou mais eficiente devido ao avanço tecnológico que permitiu a produção em áreas que antes eram improdutivas (VILARINHO, 2015)

Entre os anos 1990 e 2009, houve um impulso para a expansão da produção agrícola, em particular no processamento da soja, para a região centro-oeste, que antes estava concentrada na região Sul (HEREDIA et al, 2010).

Um dos fatores que influenciou a evolução do agronegócio brasileiro neste período foi a estabilização da economia brasileira com a criação do Plano Real (GIANEZINI, 2012). Neste contexto de intervenção estatal se alia também a presença de grupos empresariais e empresas multinacionais que contribuíram para implementar mudanças nos processos sociais do campo, colocando em curso a formação do paradigma do agronegócio (HEREDIA et al, 2010).

\section{DISCUSSÃO}

De acordo com a análise aos dados apresentados na literatura pode-se observar que há consenso entre os autores de que o agronegócio brasileiro é uma atividade que tem grande representatividade dentro d economia do país.

Em relação ao crescimento do agronegócio verifica-se que embora o Brasil seja reconhecidamente um país, com grande potencial, ainda existem diversos fatores que se tornam um obstáculo para a alavancagem desta atividade. Um dos desafios é a garantir maior participação na liberalização comercial, tendo maior contrapartida dos países desenvolvidos, como Estados Unidos e União Europeia visando obter maior ingresso aos mercados agroindustriais internacionais (FIGUEREDO et al, 2010).

Alguns autores demonstram que o êxito do agronegócio brasileiro está relacionado à eficiência dos serviços públicos de infraestrutura, sobretudo a precariedade dos modais de transporte rodoviário e inovações tecnológicas do Governo Federal (NOVAES et al, 2010) (ROLDÃO; MACIEL JÚNIOR, 2015).

A política fiscal brasileira impõe ao setor de agronegócio uma elevada carga tributária. Nos países integrantes do MERCOSUL que são concorrentes, os tributos cobrados são inferiores aos praticados pelo governo do Brasil. Neste sentido a reforma tributária contribuirá significativamente par promover maior competitividade ao agronegócio brasileiro, pois, a diminuição da arrecadação implica no aumento da produção ( SANT'ANA, 2010).

Novaes et al (2010) aponta que a redução do custo Brasil, a busca por novos mercados, conciliar o desenvolvimento econômico com a sustentabilidade, realizar investimento em pesquisa são os s maiores desafios do agronegócio brasileiro nos próximos anos. Ampliar a oferta de crédito, a revisar políticas econômicas, sobretudo ampliar o crédito rural, bem como a facilitação de acesso ao mesmo, adotando medidas de desburocratização, contribui para a diversificação do agronegócio brasileiro (REIS, 2013) (ROLDÃO; MACIEL JÚNIOR, 2015).

A revisão das políticas econômicas, sobretudo ampliar o crédito rural, bem como a facilitação de acesso ao mesmo, adotando medidas de desburocratização, maior controle 
sanitário, a compatibilização com a legislação ambiental que exige a implantação de ações legais e a redução da carga tributária são ações que contribuem para alavancar o agronegócio brasileiro (ROLDÃO; MACIEL JÚNIOR, 2015).

\section{CONSIDERAÇÕES FINAIS}

Este estudo teve por objetivo analisar, por meio de uma revisão de literatura, os desafios e perspectivas para o agronegócio brasileiro.

As considerações teóricas apontadas neste estudo demonstram que o Brasil é um país com recursos favoráveis à produção agrícola e que possui capacidade para ampliar a área de produção. Esta característica faz com que se torne um local apropriado para o desenvolvimento do agronegócio. A partir da revisão de literatura ficou demonstrado que o agronegócio brasileiro é uma atividade que tem grande representatividade dentro da economia do país.

Em relação ao crescimento do agronegócio, foi evidenciado que o Brasil possui um grande potencial para o desenvolvimento do agronegócio, no entanto, ainda existem diversos fatores que se tornam um obstáculo para a alavancagem desta atividade.

Constatou-se que um dos desafios é a garantir maior participação na liberalização comercial, tendo maior contrapartida dos países desenvolvidos, como Estados Unidos e União Europeia visando obter maior ingresso aos mercados agroindustriais internacionais.

O presente estudo sugere que futuras pesquisas nesta área do conhecimento a fim de oferecer suporte aos profissionais que atuam neste campo o conhecimento.

\section{REFERÊNCIAS}

BORGES, A. O grande desafio do agronegócio no Brasil.

Disponível em: <http://www.empreendedorrural.com.br>. Acesso em: 2 de fev de 2018

BRASIL. Ministério Agricultura, Pecuária e Abastecimento. Plano Agrícola e Pecuário 2015/2016. Disponível em :< http://www.agricultura.gov.br/arq_editor/PPT\%20PAP\%20alterado.pdf >Acesso em: de fev de 2018

BATALHA, M. O.; SILVA, A. L. Gerenciamento de sistemas agroindustriais: definições, especificidades e correntes metodológicas. In: BATALHA, M. O. (Coord.) Gestão agroindustrial:GEPAl: Grupo de estudos e pesquisas agroindustriais - 3. ed. - São Paulo: Atlas, 2007. p. 1-60.

CLEMENTS, E.A.; FERNANDES, B.M. Land Grabbing, Agribusiness and the Peasantry in Brazil and Mozambique. Agrarian South: Journal of Political Economy April 2013 vol. 2 no. 1 41-69

CONTINI, E. Dinamismo do Agronegócio Brasileiro.

Disponível em: <http://www.agronline.com.br/artigos/artigo>. Acesso em: 23 de janeiro de 2018.

CRIBB, A.Y. Determinantes da Transferência de Tecnologia na Agroindústria Brasileira de Alimentos: Identificação e Caracterização. Journal of Technology Management \& Innovation, Santiago, v. 4, n. 3, p. 89-100, oct. 2009.

DEAGRO. Departamento do Agronegócio da Fiesp. Balança Comercial Brasileira do Agronegócio Consolidado 2015. Disponível em :< http://az545403.vo.msecnd.net/uploads/2016/01/bca_2015.12-consolidado-ano.pdf >Acesso em: 23 de janeiro de 2018. 
FAO . Food and Agriculture Organization of United Nations. 2015. Disponível em:

<http://www.fao.org/economic/ess/ess-fs/fs-data/essfadata/en/>. Acesso em: 20 de jan de 2018.

GIANEZINI, M. Determinantes da Expansão da Bovinocultura na Amazônia Legal Mato-

Grossense.Doutorado. 130 fl. Universidade Federal do Rio Grande do Sul, Centro de Estudos e Pesquisas em Agronegócios, Programa de Pós -Graduação em Agronegócios,Porto Alegre, BR$\mathrm{R}, 2012$

HEREDIA, B.et al. Sociedade e Economia do "Agronegócio" no Brasil. Rev. bras. Ci. Soc., São Paulo , v. 25, n. 74, p. 159-176, Oct. 2010.

LIMA, L.C. et al. Espaço, sistemas técnicos a expansão do agronegócio no estado do Ceará, 2011. Universidade Federal da Paraíba.Disponível em $:<$ http://www.geociencias.ufpb.br/posgrad/sernne/artigo43.pdf>Acesso em 12 de janeiro de 2018.

NOVAES, A. Análise dos fatores críticos de sucesso do agronegócio brasileiro. Anais... 48응 Congresso SOBER- Sociedade Brasileira de Economia, Administração e Sociologia Rural. Campo Grande, 25 a 28 de julho de 2009. Disponível em :< http://www.sober.org.br/palestra/15/839.pdf>Acesso em: 12 jan 2018.

PRIORI, A., et al. História do Paraná: séculos XIX e XX [online]. Maringá: Eduem, 2012. A modernização do campo e o êxodo rural. pp. 115-127

REDIN, E.;FIALHO, M.A.V. Política agrícola brasileira: uma análise histórica da inserção da agricultura familiar. Anais... 48 ongresso SOBRE- Sociedade Economia Administração e Sociologia Rural- 25 A 28 de julho de 2010. Campo Grande-MT.

REIS, D.Z. O crédito como fator determinante no desenvolvimento do agronegócio brasileiro. Universidade de Brasília - UNB -Faculdade Unb Planaltina - FUP -Trabalho de Conclusão de Curso Gestão do Agronegócio, Brasília, 2012. Disponível em :< http://bdm.unb.br/bitstream/10483/3960/1/2012_DiogoZansavioReis.pdf>Acesso em: 12 jan de 2018.

ROLDÃO,G.S.; MACIEL JUNIOR, V. AGRONEGÓCIO - O GRANDE GERADOR DE RIQUEZAS PARA O BRASIL, 2015. In: SILVA, José Carlos da et al. Agronegócio sustentável . Uberlândia: Composer, 2015.

SANT'ANA, J. Análise da viabilidade operacional da implantação do Terminal Intermodal de Cargas no estado de Mato Grosso do Sul: um estudo sobre a importância na integração dos modais de transporte para o agronegócio.In: ENANGRAD, 21.,2010, Brasília. Anais... Brasília: ANGRAD, 2009.

VILARINHO, M. R. Questões sanitárias e o agronegócio brasileiro.Disponível em: <http://www.embrapa.br/embrapa/ >. Acesso em: 21 de jan de 2018.

WILKINSON, John. Transformações e perspectivas dos agronegócios brasileiros. R. Bras. Zootec., v.39, p.26-34, 2010. https://doi.org/10.1590/S1516-35982010001300004 